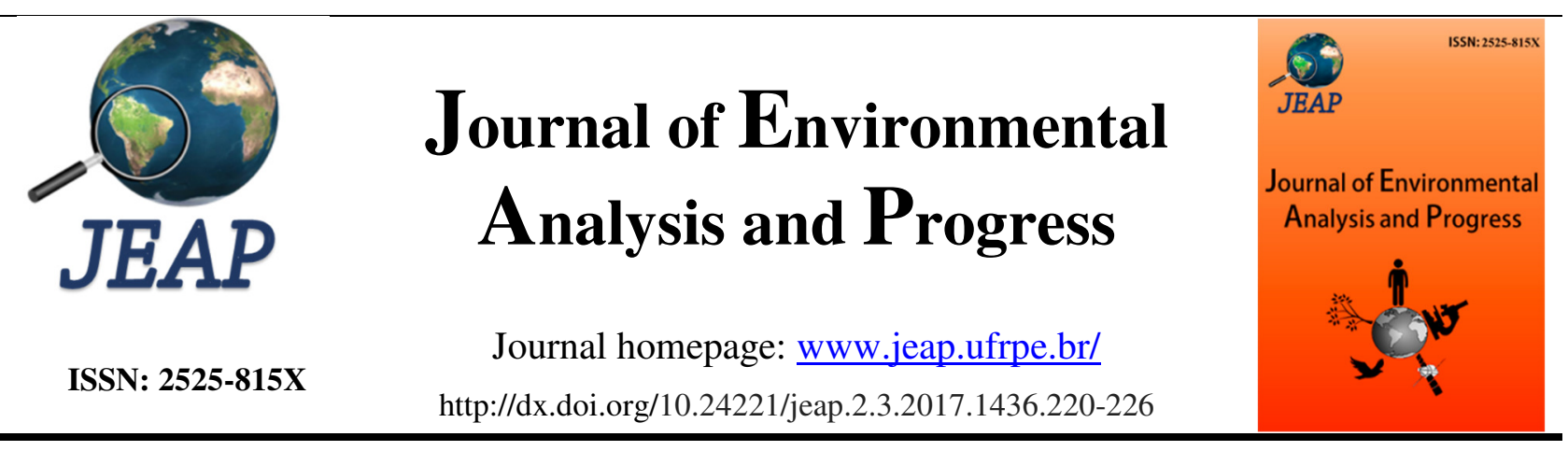

\title{
Variáveis meteorológicas e crescimento do arroz irrigado
}

\section{Meteorological variables and growth of irrigated rice}

\author{
Lucas Fernando Carvalho da Conceição ${ }^{\mathrm{a}}$, Luciana Barros Pinto ${ }^{\mathrm{b}}$, Santiago Vianna Cuadra ${ }^{\mathrm{b}}$, Ivan \\ Rodrigues de Almeida ${ }^{\mathrm{b}}$, Silvio Steinmetz ${ }^{\mathrm{b}}$ \\ ${ }^{\text {a }}$ Universidade Federal de Pelotas, Departamento de Meteorologia, Pelotas, Rio Grande do Sul, Brasil. CEP: $96010-900$. \\ E-mail: luucascarvalho93@gmail.com; luciana.pinto@ufpel.edu.br. \\ ${ }^{\mathrm{b}}$ Laboratório de Agrometeorologia da Embrapa Clima Temperado, Pelotas, Rio Grande do Sul, Brasil. CEP:96010-971. \\ E-mail: santiago.cuadra@embrapa.br; ivan.almeida@embrapa.br; silvio.steinmetz@embrapa.br.
}

\begin{abstract}
A R T I C L E I N F O
Recebido 27 Jun 2017

Aceito 25 Jul 2017

Publicado 31 Jul 2017

A B S T R A C T

The rice crop is of extreme importance to the economy of southern Brazil, mostly to the State of Rio Grande do Sul/RS, which is the largest national producer of irrigated rice. Analysis during the phenological development of plant growth (sources) of different cultivars and their interactions (feedback) with meteorological variables, has become increasingly important because they provide more accurate adjustments for optimal indication time of sowing of crops in various environments. The objective of this study was to analyze the development of different phenological stages of three irrigated rice cultivars: BRS Querência, BRS Pampeira and BRS Pampa CL. It was conducted a field experiment with three different cultivars and in three seasons of sowings, at the Experimental Station of Embrapa, municipality of Capão do Leão, Rio Grande do Sul. The evaluations were performed with samples of green leaves, dead leaves, stalks and panicles in four seasons, these being, carried out in a linear meter with four repetitions and based on phenological stages of each cultivar. It can be concluded that the predominance of development of cultivars was variable and dependent on the phenological stage in which were analyzed, the weather variables were favorable to the development of three different types of irrigated rice.
\end{abstract}

Keywords: Temperature, phenology, Rio Grande do Sul.

\section{R E S U M O}

A cultura orizícola é de extrema importância para a economia da região sul do Brasil, principalmente para o estado do Rio Grande do Sul/RS, que é o maior produtor nacional de arroz irrigado. Análises durante o desenvolvimento fenológico dos componentes de crescimento das plantas (fontes) de diferentes cultivares e suas interações (feedback) com as variáveis meteorológicas, vem se tornando cada vez mais importantes, pois proporcionam ajustes mais acurados para a indicação ideal $\mathrm{da}(\mathrm{s})$ época(s) de semeadura das culturas em diversos ambientes. O objetivo do estudo foi analisar o desenvolvimento dos diferentes estádios fenológicos de três cultivares de arroz irrigado: BRS Querência, BRS Pampeira e BRS Pampa CL. Foi conduzido um experimento de campo com três diferentes cultivares e em três épocas de semeaduras, na Estação Experimental da Embrapa Terras Baixas, município de Capão do Leão, Rio Grande do Sul. As avaliações foram realizadas com amostras de folhas verdes, folhas mortas, colmos e panículas em quatro épocas de coleta, sendo estas, realizadas em um metro linear com quatro repetições e baseadas nos estádios fenológicos de cada cultivar. Pode-se concluir que o predomínio de desenvolvimento das cultivares foi variável e dependente do estádio fenológico em que eram 
analisadas, as variáveis meteorológicas apresentaram-se favoráveis ao desenvolvimento dos três diferentes tipos de arroz irrigado analisados.

Palavras-Chave: Temperatura, fenologia, Rio Grande do Sul.

\section{Introdução}

O cultivo do arroz, responsável pelo segundo maior volume de produção mundial em grãos, ocupa uma área de, aproximadamente, 168 milhões de hectares, com uma produção de 741 milhões de toneladas de grãos, ambas em nível global. A América do Sul é o segundo maior produtor de grãos, tendo o Brasil como principal produtor (11 a 13 milhões de toneladas) e consumidor (Sosbai, 2016).

A cultura do arroz é uma das mais importantes no quesito socioeconômico nacional e apresentou significativos incrementos em produtividade ao longo das últimas décadas. $\mathrm{Na}$ safra 1980/81, no Brasil, foram cultivados 6,6 milhões de hectares, com produtividade de 1,3 ton.ha ${ }^{-1}$, enquanto que na safra de 2002/03, em uma área de 3,2 milhões de hectares, a produtividade foi de 3,45 ton.ha ${ }^{-1}$, totalizando um incremento de 165\% (Azambuja et al., 2004).

O grande impulsionador do crescimento de produtividade do arroz no Brasil foi o Rio Grande do Sul, que aumentou em 111,21\% sua produção entre as safras 1990/91 e 2014/15. Atualmente, o RS, sozinho, é responsável por aproximadamente $66,66 \%$ de toda produção do grão no Brasil (Conab, 2015).

Diversos fatores são determinantes para o desenvolvimento da cultura no estado, como características de solo e meteorológicas, sendo radiação solar, precipitação e temperaturas os predominantes (Sosbai \& Castro, 2016). O conceito de graus-dia, definido como a disponibilidade energética do meio e caracterizado como o acúmulo diário de temperaturas que se situam acima da condição mínima (temperatura base inferior) e abaixo da máxima (temperatura base superior) exigida pela planta, é um dos principais indicadores de crescimento da planta e através dele é possível estimar os estádios de desenvolvimento da cultura (Ometto, 1981; Steinmetz et al., 2004; Steinmetz et al., 2009).

Neste contexto, o objetivo deste estudo é analisar o desenvolvimento de componentes da cultura do arroz nos diferentes estádios fenológicos de três cultivares de arroz irrigado (BRS Querência, BRS Pampeira e BRS Pampa CL) desenvolvidas pela EMBRAPA.

\section{Material e Métodos}

Neste estudo foi conduzido um experimento de campo na Estação Experimental
Terras Baixas (ETB) da Embrapa Clima Temperado, município de Capão do Leão-RS, na safra de 2016/2017, com três tipos diferentes de cultivares de arroz irrigado (BRS Querência, BRS Pampa CL e BRS Pampeira) escolhidas em função de sua considerável comercialidade e consumo no mercado orizícola. Estas cultivares foram semeadas em campo, em três épocas distintas (Tabela 1), em grandes parcelas para cada cultivar, e coletadas amostras destrutivas, com quatro repetições no espaço de um metro linear.

Tabela 1. Épocas de semeaduras do experimento conduzido no Campo Experimental da Embrapa Terras Baixas, Capão do Leão-RS. Fonte: Conceição et al. (2017).

\begin{tabular}{cc}
\hline Época & Data de semeadura \\
\hline 1 & $19 / 09 / 2016$ \\
2 & $31 / 10 / 2016$ \\
3 & $21 / 11 / 2016$ \\
\hline
\end{tabular}

Considerando os estádios das cultivares, foram estabelecidas coletas em dias definidos do desenvolvimento planejado das plantas, que foram: 19/12/2016 - representando 49 dias após a semeadura, 17/01/2017 - 77 dias após a semeadura, 20/02/2017 - totalizando um montante de 112 dias e 13/03/2017 - totalizando 133 dias pós semeadura. Em cada coleta foram avaliados o peso fresco total (g) de plantas obtidas em um metro linear, com quatro repetições em cada parcela e, em seguida, foi selecionado $10 \%$ de cada amostra total, e contabilizado o número de perfilhos da subamostra e realizado o estudo fenológico para obtenção do peso da massa fresca das componentes (folha verde, folha morta, colmo e panícula). As amostras das componentes foram mantidas em uma estufa à temperatura média de $50^{\circ} \mathrm{C}$, durante um período de 20 a 25 dias, para a obtenção do peso da massa seca.

As datas para a realização da amostragem no campo foram baseadas no estádio fenológico das plantas, que foram estimados através do software GD Arroz (Steinmetz et al., 2015). Através do uso desta ferramenta, foram estabelecidas as datas de coleta considerando o estádio fenológico de cada cultivar, respeitando os diferentes ciclos de desenvolvimento, como podese observar na Tabela 2, que apresenta as datas dos estágios fenológicos para a época de semeadura 2. 
Tabela 2. Datas estimadas das coletas destrutivas baseadas na projeção do software GD Arroz (http://agromet.cpact.embrapa.br), com base na escala fenológica proposta por Counce, Keisling \& Mitchell (2000), para a segunda época de semeadura (31/10/2016). Fonte: Conceição et al. (2017).

\begin{tabular}{lcccccc}
\hline Época 2 & $\begin{array}{c}\text { Grupo de } \\
\text { maturação }\end{array}$ & $\begin{array}{c}\text { Ciclo } \\
\text { (dias) }\end{array}$ & V10 & R2 & R4 & R9 \\
\hline BRS Querência & P1 & 110 & $14 / 01 / 2017$ & $22 / 01 / 2017$ & $05 / 02 / 2017$ & $17 / 03 / 2017$ \\
BRS Pampa & P2 & 118 & $14 / 01 / 2017$ & $26 / 01 / 2017$ & $08 / 02 / 2017$ & $16 / 03 / 2017$ \\
BRS Pampeira & M & 132 & $14 / 01 / 2017$ & $03 / 02 / 2017$ & $21 / 02 / 2017$ & $28 / 03 / 2017$ \\
\hline
\end{tabular}

Os resultados apresentados estão divididos em duas partes, na primeira parte é apresentada a análise das componentes de crescimento, folha verde e colmo (gramas), apenas para a época com dados mais representativos (época de semeadura 2) (Tabela 2); na segunda parte, os dados foram submetidos à análise de variância e, as médias, quando significativas, foram comparadas pelo teste de Tukey a 5\% de probabilidade, considerando as épocas de semeadura 1 e 2 . As duas etapas foram feitas com os dados das cultivares BRS Querência, BRS Pampa CL e BRS Pampeira. Foram geradas médias baseadas no peso da massa fresca das subamostras das quatro repetições, referentes às variáveis definidas.

A investigação das variáveis meteorológicas foi realizada entre o intervalo temporal da época de semeadura 2 até a última coleta geral do experimento, baseada na análise de dados diários de temperatura máxima e mínima $\left({ }^{\circ} \mathrm{C}\right)$, precipitação acumulada $(\mathrm{mm})$ e radiação solar diária $\left(\mathrm{MJ} \cdot \mathrm{m}^{-2} \cdot \mathrm{dia}^{-1}\right)$ obtidos junto à estação agroclimatológica da Embrapa Clima temperado, localizada na latitude de 31 $52^{\circ} 0^{\prime}$ 'S e longitude de $52^{\circ} 21^{\prime} 24^{\prime \prime} \mathrm{W}$.

\section{Resultados}

As análises das variáveis meteorológicas foram realizadas ao longo de todo os dias após a segunda época de semeadura (DAS), visando analisar o comportamento da temperatura máxima diária, temperatura mínima diária, precipitação acumulada diária (Figura 1) e radiação solar (Figura 2) e a relação com os componentes de crescimento (folhas verdes e colmos) das cultivares BRS Querência, BRS Pampeira e BRS Pampa CL (Figuras 3 e 4 ).

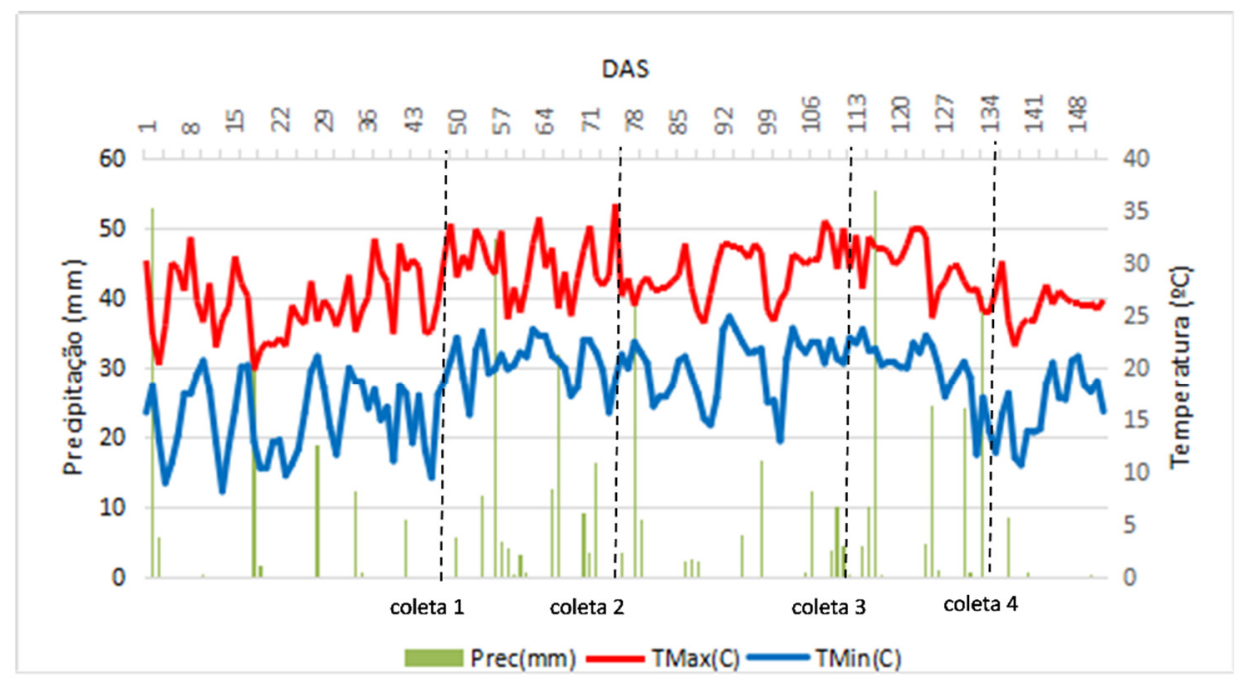

Figura 1. Comportamento das temperaturas mínimas e máximas diárias e precipitação em relação aos dias após a semeadura (DAS) da época 2, no Campo Experimental da Embrapa Terras Baixas, Capão do Leão-RS

Observou-se que, durante o período compreendido entre início e fim do experimento, foram registradas temperaturas mínimas baixas $\left(8,1^{\circ} \mathrm{C}\right.$ ) (Figura 1), principalmente no período inicial correspondente aos primeiros $40 \mathrm{DAS}$, onde as cultivares ainda se encontravam no estádio vegetativo. Após a coleta 1 (49 DAS), a temperatura mínima apresentou uma considerável elevação, atingindo máximo de $22,9^{\circ} \mathrm{C}$, e mantevese acima de $15^{\circ} \mathrm{C}$ até os $80 \mathrm{DAS}$, oscilando entre 14 e $24^{\circ} \mathrm{C}$ até a coleta 4 (133 DAS), quando foi registrada uma queda nos valores $\left(11,9^{\circ} \mathrm{C}\right)$. 


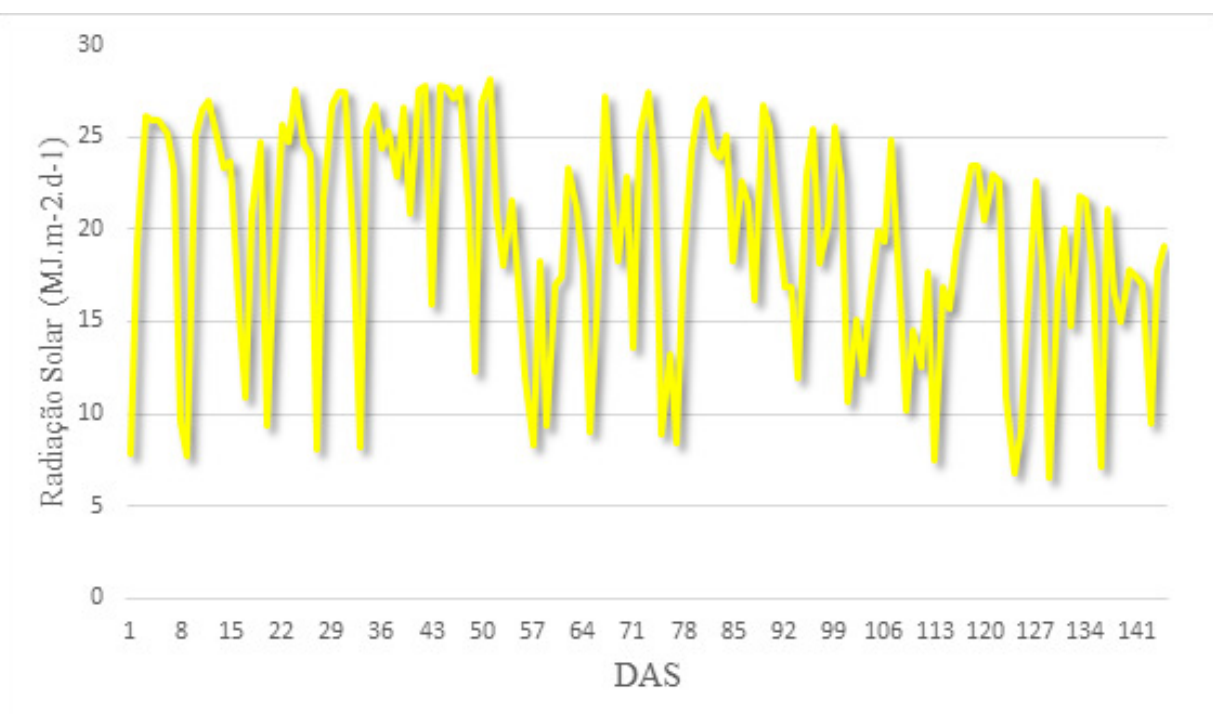

Figura 2. Comportamento da radiação solar diária em relação aos dias após a semeadura da época 2 no Campo Experimental da Embrapa Terras Baixas, Capão do Leão-RS.

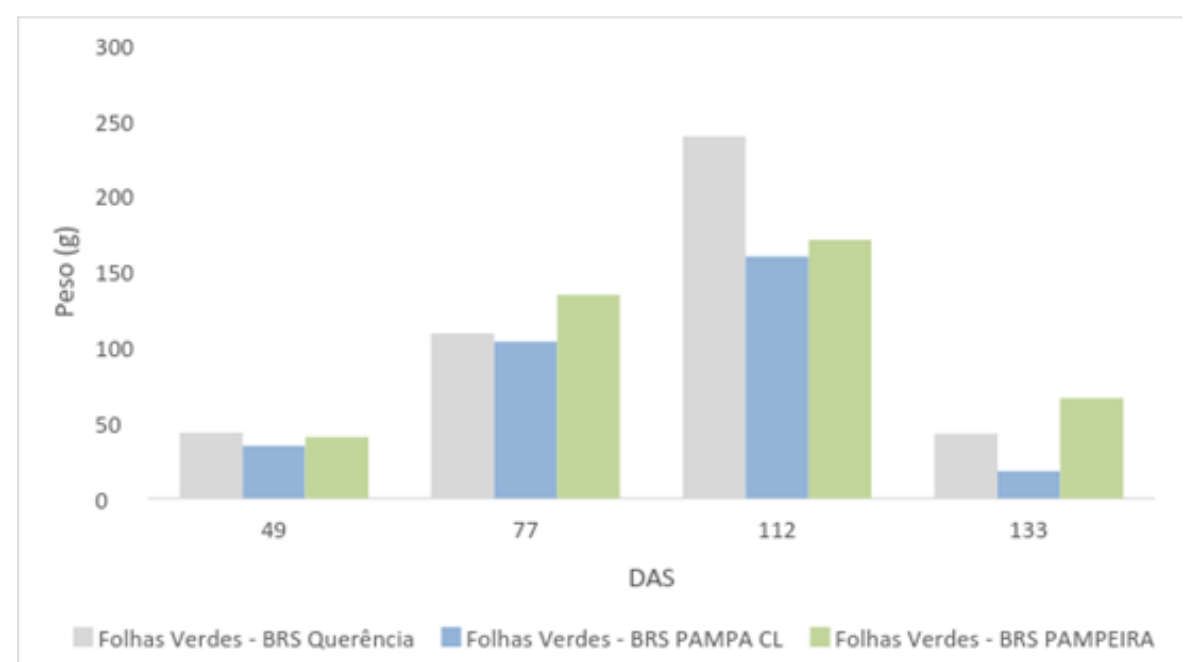

Figura 3. Desenvolvimento da componente folhas verdes (gramas) ao longo da época 2 em relação aos dias após a semeadura e também as quatro amostragens de campo realizadas nos respectivos dias no Campo Experimental da Embrapa Terras Baixas, Capão do Leão-RS.

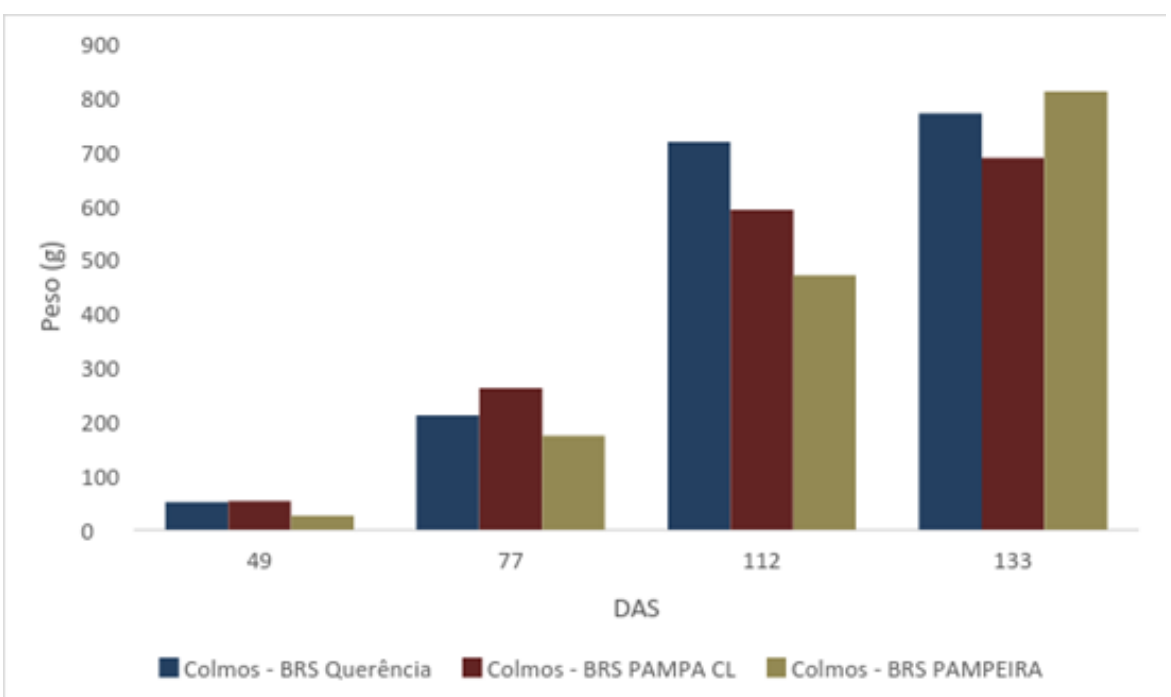

Figura 4. Desenvolvimento da componente colmos (gramas) ao longo da época 2 em relação aos dias após a semeadura e também as quatro amostragens de campo realizadas nos respectivos dias no Campo Experimental da Embrapa Terras Baixas, Capão do Leão-RS. 
Durante o período experimental, foi registrado um total de precipitação de $567,5 \mathrm{~mm}$ acumulados, com máximo após a coleta 3, chegando a atingir $55,3 \mathrm{~mm}$ aos 115 DAS, corresponde ao dia 23/02/2017. A precipitação média diária para todo o período foi de $3,76 \mathrm{~mm}$. Pode-se notar que, após elevados índices de precipitação, ocorreram declínios consideráveis nos valores das temperaturas máximas e mínimas.

A radiação solar (Figura 2) apresentou seu valor máximo $\left(28,17 \mathrm{MJ} \cdot \mathrm{m}^{-2}\right.$.dia $\left.\mathrm{di}^{-1}\right)$ entre as coletas 1 e 2, mais precisamente aos 51 DAS (21/12/2016) e, mínimo $\left(6,57 \mathrm{MJ} \cdot \mathrm{m}^{-2} \cdot \mathrm{dia}^{-1}\right)$ aos 129 DAS (09/03/2017) próximo a última coleta do experimento e, consequentemente, próximo ao fim do período avaliado. O comportamento da radiação solar apresentou uma tendência decrescente no período estudado, apresentando seus maiores valores próximos ao período compreendido pelo final de novembro e início de dezembro e menores valores no final de fevereiro e início de março (Figura 2).

$\mathrm{Na}$ análise comparativa entre as 3 cultivares selecionadas (Figura 3), pode-se perceber que na primeira coleta, correspondente ao estádio vegetativo (realizada aos 49 DAS), houve uma uniformidade do peso de folhas verdes entre as BRS, com ligeira predominância da BRS Querência. Posteriormente, na segunda coleta, realizada aos 77 DAS, quando que as cultivares tinham atingido o estádio reprodutivo inicial (R2), a cultivar BRS PAMPEIRA se destacou, apresentando o maior peso de folhas verdes $(134,76 \mathrm{~g})$. Aos 112 DAS, na terceira coleta, a cultivar BRS Querência voltou a se destacar com o maior peso $(239,71 \mathrm{~g})$, quando, também, foram registrados os maiores valores para todas as cultivares por apresentar um estádio mais desenvolvido da cultura (R4), em relação aos anteriores. A última coleta, quando as cultivares apresentavam o desenvolvimento totalmente finalizado, foi marcado pela queda acentuada dos valores de folhas verdes para todas as BRS.

O desenvolvimento dos colmos (Figura 4) apresentou um crescimento contínuo a cada coleta, atingindo seus valores máximos no final do experimento. A coleta 1, aos 49 DAS, foi marcada pelo predomínio da BRS Pampa CL (53,69 g), com valores mínimos para a BRS Pampeira (26,61 g), fato que também foi constatado na segunda coleta, com valores de 262,23 g e 174,26 g, respectivamente. $\mathrm{Na}$ terceira coleta, quando as cultivares apresentavam um estádio avançado de crescimento, houve uma mudança do padrão, pois a cultivar BRS Querência mostrou o maior peso de colmos (717,48 g). Na última coleta (13/03/2017), a cultivar BRS Pampeira que apresentou os menores valores, passou a ser a cultivar em destaque com o maior peso $(810,38 \mathrm{~g})$.

Pela análise do peso fresco de folhas verdes (Tabela 3), dentro de cada época de semeadura, letra maiúscula, observa-se que para a época 1 de semeadura, na coleta 1 não há variação entre as cultivares. Para a segunda coleta, as BRS Querência e Pampa apresentaram maiores valores em relação à BRS Pampeira. Para a terceira coleta, as BRS Querência e Pampeira apresentam os maiores valores de folhas frescas. Na quarta coleta, mesmo a BRS Pampeira tendo média de $40,9 \mathrm{~g}$ e as outras duas não apresentando mais folhas verdes, os valores médios não diferem entre elas. Para a época 2 de semeadura, observa-se que apenas na terceira coleta existe uma diferença entre as cultivares, em que a BRS Querência apresenta maior valor do que as outras.

Comparando as mesmas cultivares, nas duas épocas (Tabela 3, letras minúsculas), nota-se que para as cultivares BRS Querência e Pampa, apenas nas coletas 2 e 3 existe a diferença entre as épocas de semeadura, onde na coleta 2, a época 1 apresentou maiores valores de massa fresca de folhas secas $(252,97 \mathrm{~g}$ e $279,11 \mathrm{~g}$, respectivamente), e na coleta 3, a época 2 apresentou maiores valores $(239,71$ g e $160,27 \mathrm{~g}$, respectivamente). Para a cultivar BRS Pampeiro, apenas a coleta 2 apresentou diferença, quando a época 1 apresentou maior valor $(199,20 \mathrm{~g})$.

Embora, pela análise de variância o peso fresco de colmo não foi significante entre as épocas de semeadura e entre as cultivares (Tabela 4), podese observar que dentro da época 1, a cultivar BRS Pampa, foi a que apresentou maiores valores em todas as coletas, mostrando um maior acúmulo de biomassa em colmos. Na época 2 de semeadura, não houve uma cultivar que apresentou maiores valores em relação às outras em todas as coletas. $\mathrm{O}$ que se observou, foi um crescimento contínuo do peso fresco de colmo em todas as cultivares.

Tabela 3: Peso da massa fresca (g) de folhas verdes para três cultivares de arroz irrigado, em função de épocas de semeadura, em quatro épocas de coletas. Fonte: EMBRAPA Clima Temperado-RS (2017).

\begin{tabular}{ccccccc}
\hline \multirow{3}{*}{ Coleta } & \multicolumn{5}{c}{ Época de semeadura } \\
\cline { 2 - 6 } & \multicolumn{7}{c}{$\mathbf{1}$} & \multicolumn{3}{c}{} & $\mathbf{2}$ \\
& Querência & Pampa & Pampeira & Querência & Pampa & Pampeira \\
\hline 1 & $24,45 \mathrm{Aa}$ & $31,18 \mathrm{Aa}$ & $26,81 \mathrm{Aa}$ & $43,54 \mathrm{Aa}$ & $34,96 \mathrm{Aa}$ & $40,79 \mathrm{Aa}$ \\
2 & $252,97 \mathrm{Aa}$ & $279,11 \mathrm{Aa}$ & $199,20 \mathrm{Ba}$ & $109,31 \mathrm{Ab}$ & $103,86 \mathrm{Ab}$ & $134,76 \mathrm{Ab}$
\end{tabular}




\begin{tabular}{ccccccc}
3 & $112,29 \mathrm{ABb}$ & $103,15 \mathrm{Bb}$ & $165,27 \mathrm{Aa}$ & $239,71 \mathrm{Aa}$ & $160,27 \mathrm{Ba}$ & $171,11 \mathrm{Ba}$ \\
4 & $0 \mathrm{Aa}$ & $0 \mathrm{Aa}$ & $40,90 \mathrm{Aa}$ & $43,05 \mathrm{Aa}$ & $18,12 \mathrm{Aa}$ & $66,31 \mathrm{Aa}$ \\
\hline $\mathrm{CV}=31,36$ & & & & \\
\hline
\end{tabular}

Em relação à variação da mesma cultivar em épocas diferentes de semeadura (Tabela 4), nota-se que a cultivar BRS Querência apresentou um comportamento diferente entre as épocas 1 e 2. $\mathrm{Na}$ época 1, seu valor máximo de colmo foi o avaliado na segunda coleta $(562,63 \mathrm{~g})$, decaindo até a quarta coleta, na época 2 , o peso fresco de colmo foi crescente ao longo das coletas. Para as cultivares BRS Pampa e BRS Pampeiro, na época 1 , o comportamento foi semelhante, apresentando dois picos, um na coleta 2 e outro na coleta 4 , enquanto na época 2 , o crescimento foi contínuo nas coletas para as duas cultivares.

Tabela 4: Peso fresco (em gramas) de colmos para três cultivares de arroz irrigado, em função de épocas de semeadura, em quatro épocas de coletas. Fonte: EMBRAPA Clima Temperado-RS (2017).

\begin{tabular}{lcccccc} 
& \multicolumn{5}{c}{ Época de semeadura } \\
\cline { 2 - 7 } Coleta & \multicolumn{7}{c}{$\mathbf{1}$} & & & $\mathbf{2}$ & \\
\hline 1 & Querência & Pampa & Pampeira & Querềncia & Pampa & Pampeira \\
2 & $43,07^{\mathrm{ns}}$ & $63,11^{\mathrm{ns}}$ & $47,24^{\mathrm{ns}}$ & 51,86 & 53,70 & 26,61 \\
3 & 562,63 & 581,15 & 299,53 & 211,77 & 262,24 & 174,27 \\
4 & 391,96 & 528,12 & 289,73 & 717,48 & 592,04 & 471,21 \\
$\mathrm{X}=422,44$ & 384,54 & 1416,87 & 500,86 & 770,49 & 687,81 & 810,38 \\
\hline
\end{tabular}

ns = não significativo

\section{Discussão}

A relação entre a temperatura e o desenvolvimento do arroz é de variação ao longo do desenvolvimento de seus estádios, onde a cultura não suporta temperaturas excessivamente baixas, nem excessivamente altas (Sosbai, 2016; Steinmetz, 2004). Da fase da germinação até a maturação é necessária uma temperatura relativamente alta, uniformemente crescente até a floração e, decrescente, após esta. As faixas de temperatura ótima variam de $20^{\circ} \mathrm{C}$ a $35^{\circ} \mathrm{C}$ para a germinação, de $30^{\circ} \mathrm{C}$ a $33^{\circ} \mathrm{C}$ para a floração e de $20^{\circ} \mathrm{C}$ a $25^{\circ} \mathrm{C}$ para a maturação (Yoshida, 1981). Sendo assim, com relação aos resultados obtidos, observou-se que, ao longo de todo o período de crescimento da segunda época de semeadura, foram registrados valores abaixo daqueles considerados ótimos dentro de cada estádio fenológico da planta.

Dentre as três cultivares, a BRS PAMPA $\mathrm{CL}$ foi a que atingiu os menores valores de folha verde em todo o ciclo analisado, enquanto as cultivares BRS Querência e BRS Pampeira alternaram os maiores valores entre si de acordo com os estádios fenológicos atingidos (Figura 3).

A variação do peso de colmos frescos pode ser atribuída, principalmente, pelas características do ciclo de cada cultivar, onde por exemplo, a BRS Pampera com ciclo médio de 132 dias, apresentou um menor acúmulo de massa do que as outras duas cultivares que são de ciclos precoces, BRS Querência (ciclo precoce 1, 110 dias) e BRS Pampa CL (ciclo precoce 2, 118 dias).

\section{Conclusão}

Constatou-se que as variáveis meteorológicas apresentaram valores médios positivos ao desenvolvimento das cultivares analisadas, na maior parte do tempo. Mesmo com as temperaturas apresentando valores fora do considerado ótimo para a cultura. Os valores máximos, bem como os mínimos, registrados para precipitação não geraram estresse para a cultura.

As componentes de crescimento selecionadas, mostraram um predomínio variável entre as cultivares diretamente relacionado ao estádio fenológico em que se encontravam e também devido aos diferentes ciclos.

Para projeções futuras, pretende-se ampliar a análise de novos componentes (peso fresco de folhas mortas e panículas e também o peso seco de folhas verdes, folhas mortas, colmos e panículas) através do incremento de dados e realizar um comparativo entre todas as 5 cultivares para as três épocas diferentes de plantio e entre as componentes da cultura.

\section{Agradecimentos}

Os autores agradecem ao Programa de PósGraduação em Meteorologia da Universidade Federal de Pelotas; à Embrapa Clima Temperado pela possibilidade de desenvolver o estudo; e à Coordenação de Aperfeiçoamento de Pessoal de Nível Superior (CAPES), pelo apoio financeiro. 


\section{Referências}

AZAMBUJA, I. H. V.; VERNETTI, F. J. JR.; MAGALHÃES, A. M. JR. 2004. Aspectos socioeconômicos da produção do arroz. In: GOMES, A. S.; JÚNIOR, A. M. M. Arroz irrigado no Sul do Brasil, pp. 23-44.

CASTRO, J. R. 2016. Determinação das incertezas nas simulações da produtividade do arroz irrigado associadas com as estimativas da radiação solar global. Dissertação de Mestrado, Universidade Federal de Pelotas, Pelotas, Rio Grande do Sul, Brasil. 67p.

CONAB-Companhia Nacional de Abastecimento. Perspectivas para a agropecuária. Disponível em: http://www.conab.gov.br/OlalaCMS/uploads/arqu ivos/15_09_24_11_44_50_perspectivas_agropecu aria_2015-16__produtos_verao.pdf. Acesso em: 9 de maio de 2017.

COUNCE, P. A.; KEISLING, T. C.; MITCHELL, A. J. 2000. A uniform, objective, and adaptative system for expressing rice development. Crop Science, v. 40, n. 2, p. 436-443.

OMETTO, J. C. 1981. Bioclimatologia vegetal. Agronômica Ceres, São Paulo.
SOCIEDADE SUL-BRASILEIRA DE ARROZ IRRIGADO (SOSBAI). 2016. Arroz irrigado: recomendações técnicas da pesquisa para o Sul do Brasil-200, Pelotas, BR.

STEINMETZ, S. 2004. Influência do clima na cultura do arroz irrigado no Rio Grande do Sul. In: GOMES, A.S; JÚNIOR, A.M.M. Arroz irrigado no Sul do Brasil, pp. 45-71.

STEINMETZ, S.; FAGUNDES, P. R. R. ; MAGALHAES JUNIOR, A. M.; DEIBLER, A. N.; PINTANEL, J. B. A.; SCHNEIDER, A. B. 2009. Influência da época de semeadura sobre o rendimento de grãos de grupos de genótipos de arroz irrigado. Anais VI Congresso Brasileiro de Arroz Irrigado, Porto Alegre-RS, Brasil.

STEINMETZ, S.; CUADRA, S. V.; PEREIRA, C. B.; SANTOS, E. L.; ALMEIDA, I. R. 2015 GD Arroz: programa baseado em graus-dia para o planejamento e tomada de decisão no manejo da adubação nitrogenada em cobertura em arroz irrigado. Anais do Congresso Brasileiro de Agrometeorologia, Lavras, MG, Brasil, UFLA. pp. 158-167.

YOSHIDA, S. 1981. Growth and development of the rice plant. Fundamentals of rice crop science. Los Banõs, Laguna. 